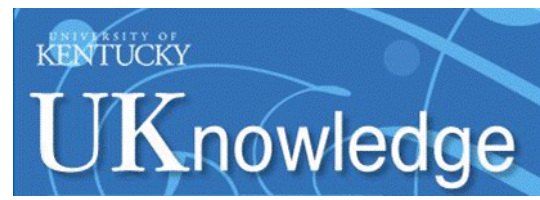

University of Kentucky

UKnowledge

$10-2020$

\title{
Combined Numerical and Experimental Determination of Ball Bearing Capacitances for Bearing Current Prediction
}

\author{
Peng Han \\ University of Kentucky, peng.han@uky.edu \\ Greg Heins \\ Regal Beloit Corporation, Australia \\ Dean Patterson \\ Regal Beloit Corporation, Australia \\ Mark Theile \\ Regal Beloit Corporation, Australia \\ Dan M. Ionel \\ University of Kentucky, dan.ionel@uky.edu
}

Follow this and additional works at: https://uknowledge.uky.edu/ece_facpub

Part of the Power and Energy Commons

Right click to open a feedback form in a new tab to let us know how this document benefits you.

\section{Repository Citation}

Han, Peng; Heins, Greg; Patterson, Dean; Theile, Mark; and Ionel, Dan M., "Combined Numerical and Experimental Determination of Ball Bearing Capacitances for Bearing Current Prediction" (2020). Electrical and Computer Engineering Faculty Publications. 46.

https://uknowledge.uky.edu/ece_facpub/46

This Conference Proceeding is brought to you for free and open access by the Electrical and Computer Engineering at UKnowledge. It has been accepted for inclusion in Electrical and Computer Engineering Faculty Publications by an authorized administrator of UKnowledge. For more information, please contact UKnowledge@lsv.uky.edu. 


\title{
Combined Numerical and Experimental Determination of Ball Bearing Capacitances for Bearing Current Prediction
}

\author{
Digital Object Identifier (DOI) \\ https://doi.org/10.1109/ECCE44975.2020.9235700
}

\section{Notes/Citation Information}

Published in 2020 IEEE Energy Conversion Congress and Exposition (ECCE).

(C) 2020 IEEE Copyright Notice. "Personal use of this material is permitted. Permission from IEEE must be obtained for all other uses, in any current or future media, including reprinting/republishing this material for advertising or promotional purposes, creating new collective works, for resale or redistribution to servers or lists, or reuse of any copyrighted component of this work in other works."

The document available for download is the authors' manuscript version that is accepted for publication. The final published version is copyrighted by IEEE and available as: P. Han, G. Heins, D. Patterson, M.

Thiele, and D.M. Ionel, "Combined numerical and experimental determination of ball bearing capacitances for bearing current prediction," 2020 IEEE Energy Conversion Congress and Exposition (ECCE), Detroit, MI, Oct. 11-15, 2020, pp. 5590-5594, doi: 10.1109/ECCE44975.2020.9235700. 


\title{
Combined Numerical and Experimental Determination of Ball Bearing Capacitances for Bearing Current Prediction
}

\author{
Peng Han, Member, IEEE, Greg Heins", Member, IEEE, Dean Patterson*, Life Fellow, IEEE, \\ Mark Thiele*, Member, IEEE, and Dan M. Ionel, Fellow, IEEE \\ SPARK Laboratory, ECE Dept., University of Kentucky, Lexington, KY, USA \\ * Regal Beloit Corporation, Australia, Rowville, VIC 3178, Australia \\ peng.han@uky.edu, greg.heins@ regalbeloit.com,dean.patterson@ regalbeloit.com \\ mark.thiele@ regalbeloit.com,dan.ionel@ieee.org
}

\begin{abstract}
High-frequency voltages across the steel ball bearings and the corresponding currents can cause premature bearing failures in electric machines driven by PWM converters. The bearing voltage, one of the most commonly-used failure indicators, depends heavily on the bearing capacitance. This paper presents a combined numerical and experimental approach for the calculation of ball bearing capacitances to address the uncertainty introduced by lubricant property, lubrication status and other metal parts, such as seals and ball retainers. Based on the obtained capacitance breakdown, the influences of temperature, speed and bearing load (radial, axial or combined) on the capacitance are studied. Measurements and associated results of bearing capacitances are provided to validate the proposed method.
\end{abstract}

Index Terms-Bearing current, bearing voltage, capacitance, electric machine, PWM inverter.

\section{INTRODUCTION}

Premature bearing failures in electric machines and electric machine-driven equipment due to bearing currents have been constantly drawing engineers' attention during the past decades [1]-[4]. High-frequency bearing voltages caused by capacitive coupling [1] and inductive coupling [5] in electric machines driven by pulse width modulation (PWM) converters are the main causes of bearing currents.

It is generally accepted that the lubricant film between the ball and bearing raceways will break down once the bearing voltage exceeds a threshold value. The accuracy of the bearing voltage prediction in steady state relies heavily on bearing and machine capacitances. Capacitances between machine parts, such as the stator-winding-to-rotor capacitance $C_{s r}$, statorwinding-to-frame capacitance $C_{s f}$ and rotor-to-frame capacitance $C_{r f}$, can be estimated by analytical equations [3], [6] or calculated by FE electrostatic solvers based on CAD files [7]. The prediction of bearing voltage transients involves not only capacitances, but also high-frequency RLC parameters of machines under study. The frequency-dependent resistances and inductances can be extracted from solving eddy current problems by finite element (FE) analysis or directly modeled in time-stepping (transient) electromagnetic FE analysis [8].

The calculation of bearing capacitance has been studied in the existing literature. A set of equations based on Hertizian contact theory were presented to calculate capacitances of roller and ball bearings in large induction motors under radial loads [9]. Bearing capacitances under various operating conditions have were measured and used to estimate the lubricant film thickness [10]. The starvation effect for grease lubricant has also been experimentally identified, which can be explained by the fact that there is not sufficient grease flowing back to the entry point between two rollover processes at high speeds and the lubricant film thickness is thus significantly reduced. Recent work on bearing current and shaft voltage predictions uses measured bearing capacitances without considering the variations in temperature, speed and load [3], [11].

This paper proposes to calculate ball bearing capacitances by performing the least squares regression analysis on experimental measurements, taking into account the uncertainty introduced by lubricant property, lubrication status and other metal parts. The bearing capacitance is broken down into three components based on the Hertzian contact theory, based on which the influences of temperature, speed and bearing load can be studied independently.

\section{Configuration and Equivalent Electric CIRCUIT FOR BALL BEARINGS}

Ball bearings are the most common type of bearing and extensively used in electric machines. According to the configuration of bearing rings, ball bearings are further classified as deep-groove ball bearings and angular contact ball bearings. This type of bearing is not only capable of taking radial loads but also axial loads. According to the bearing material, ball bearings are categorized as steel ball bearings, hybrid ceramic ball bearings and full ceramic bearings. Shown in Fig. 1a and Fig. $1 \mathrm{~b}$ are steel ball bearings with metal seal removed and full ceramic bearings.

A standard deep-groove ball bearing consists of a number of rolling balls and two concentric rings, which are made of steel for steel and hybrid ceramic ball bearings. In full ceramic ball bearings, all the balls and rings are made of ceramics, such as Silicon nitride $\left(\mathrm{Si}_{3} \mathrm{~N}_{4}\right)$ and Zirconium dioxide $\left(\mathrm{ZrO}_{2}\right)$. Besides the balls and rings, there are also ball retainers and grease seals in bearings. Ball retainers or ball cages are used to separate the balls, maintain the symmetrical radial spacing of balls and in most cases, hold the bearing together. Grease 


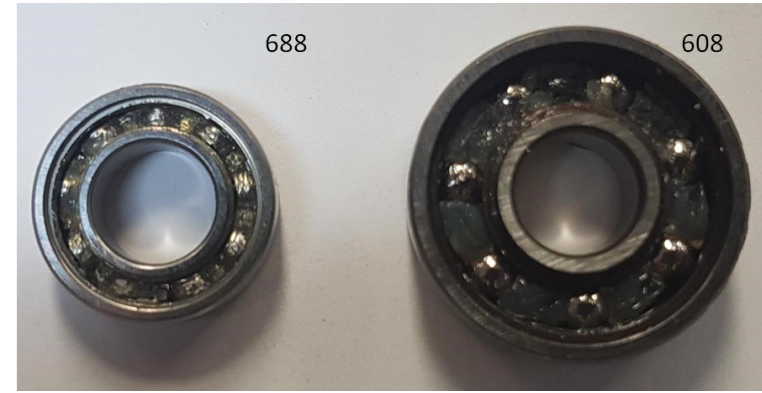

(a)

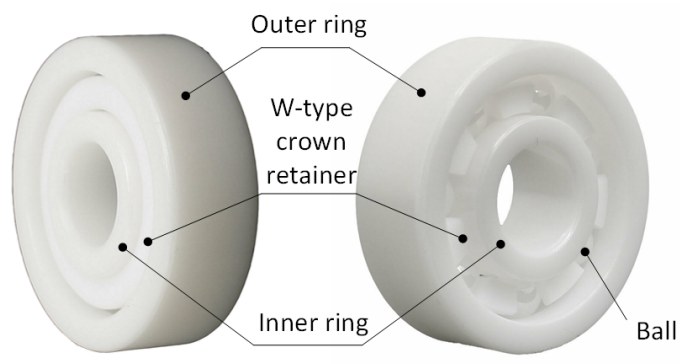

(b)

Fig. 1. Deep-groove ball bearings: (a) steel ball bearings, (b) full ceramic bearing.

seals are used to protect bearings from excess grease loss and contamination. Both the cage and seal can be metals, which introduce additional capacitances between the outer and inner rings.

Based on the physical construction, the steel ball bearing can be modeled as a combination of capacitances, resistances, and voltage-controlled switches [1], as illustrated in Fig. 2, where $R_{i r}$ and $R_{o r}$ represent the resistances of the inner and outer ring, respectively. There are $N_{b}$ balls in parallel, each having an effective resistance $R_{b, i}$.

Considering each ball is immersed in the lubricant, each ball develops two capacitances, i.e., $C_{b-i r, i}$ and $C_{b-o r, i}$, linking the inner and outer rings. Between balls, the inner and outer rings are separated by the lubricant and/or air, and an additional capacitance $C_{g, i}$ is formed. The ball retainer and seals, if made of metal, will also introduce capacitive coupling between the inner and outer races. Voltage-controlled switches are included to consider the possible breakdown of the lubricant. Once the voltage across the bearing lubricant film exceeds the threshold value, i.e., $V_{b}>V_{t h}$, the electrical discharge machining (EDM) will occur and the bearing turns into a resistor from an RC circuit. Combining the individual components results in a reduced-order bearing model, which consists of a resistance $R_{b}$ in series with the parallel connection of a capacitance $C_{b}$ and a voltage-controlled switch $S_{b}$.

For hybrid ceramic ball bearings and full ceramic bearings, the bearing model is a pure capacitor with mixed dielectrics, i.e., the ceramic, lubricant and air. Similar to steel ball bearings, metal retainers and seals will also introduce additional capacitances between inner and outer rings.
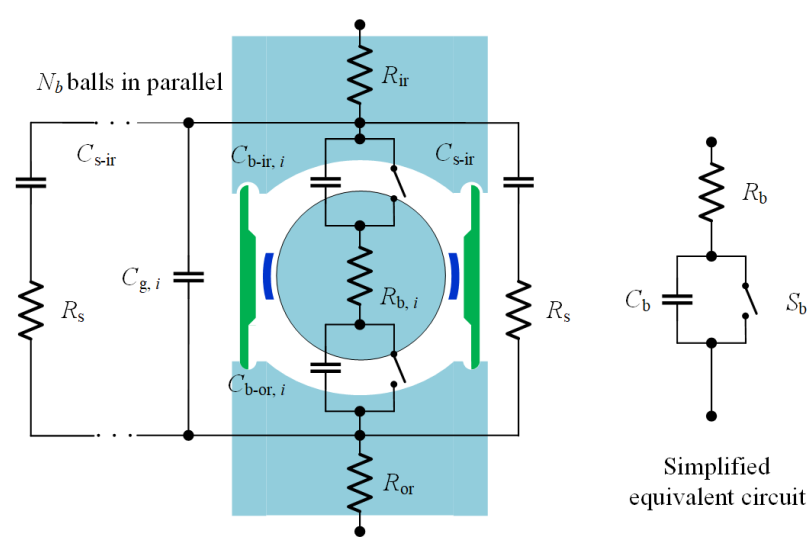

Simplified equivalent circuit

Fig. 2. Equivalent electric circuit model of steel ball bearings with metal ball retainers and seals

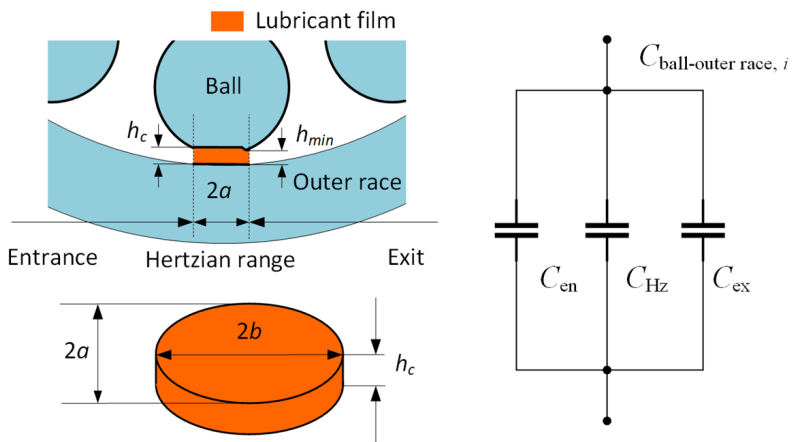

Fig. 3. Schematic of the lubricant film between the rolling ball and outer raceway, and the corresponding equivalent electric circuit.

\section{CAlculation of BeARing CAPACitAnCE}

For steel ball bearings, the key to calculate the capacitance between the inner and outer races lies in the estimation of the lubricant film thickness and contact area, which depends on the bearing geometry, lubricant property, lubrication status, speed and load. According to the Hertzian theory, the theoretical contact area is elliptical between a rolling ball and raceway, as illustrated in Fig. 3. The capacitance between each ball and the inner or outer raceway consists of three elements-the capacitance for the Hertzian ellipse $C_{H z}$, the capacitance for the entrance $C_{e n}$ and the capacitance for the exit $C_{e x}$.

The central film thickness $h_{c}$ can be calculated by the following formula [12]:

$$
h_{c}=2.69 \bar{U}_{r}^{0.67}\left(\alpha E_{e q}\right)^{0.53} \bar{W}^{-0.067}\left(1-e^{-0.73 k}\right),
$$

where $\alpha$ is the viscosity-pressure coefficient. $\bar{U}_{r}$ and $\bar{W}$ are dimensionless velocity and load, respectively, defined by:

$$
\begin{gathered}
\bar{U}_{r}=\mu_{0} U_{r}\left(E_{e q} R_{x}\right)^{-1}, \\
\bar{W}=W\left(E_{e q} R_{x}^{2}\right)^{-1} .
\end{gathered}
$$

where $U_{r}$ is the rolling velocity, $\mu_{0}$ the viscosity of the lubricant at atmospheric pressure and bearing operating temperature, $W$ the load on one rolling ball. $E_{e q}$ is the equivalent 
TABLE I

Contact Angle, Film Thickness and Capacitance Breakdown at 1,200 R/MIN WITH DIFFERENT LOADS.

\begin{tabular}{ccccccc}
\hline $\begin{array}{c}\text { Axial load } \\
{[\mathrm{N}]}\end{array}$ & $\begin{array}{c}\text { Contact angle } \\
{[\mathrm{rad}]}\end{array}$ & $\begin{array}{c}h_{c} \\
{[\mu \mathrm{m}]}\end{array}$ & $\begin{array}{c}h_{\min } \\
{[\mu \mathrm{m}]}\end{array}$ & $\begin{array}{c}C_{H z, i} \\
{[\mathrm{pF}]}\end{array}$ & $\begin{array}{c}C_{e n, i}+C_{e x, i} \\
{[\mathrm{pF}]}\end{array}$ & $\begin{array}{c}C_{b} \\
{[\mathrm{pF}]}\end{array}$ \\
\hline \multirow{2}{*}{0} & & 0.069 & 0.056 & 1.30 & 13.39 & \\
\hline \multirow{2}{*}{49} & 0.047 & 0.112 & 0.091 & 1.12 & 15.81 & 55.06 \\
\hline \multirow{2}{*}{98} & 0.175 & 0.054 & 0.042 & 23.85 & 13.41 & \\
& & 0.068 & 0.068 & 18.17 & 15.80 & 124.39 \\
\hline
\end{tabular}

modulus of elasticity and can be calculated by:

$$
E_{e q}=\frac{2}{\frac{1-v_{1}^{2}}{E_{1}}+\frac{1-v_{2}^{2}}{E_{2}}} .
$$

where "1" and "2" in subscripts denote the two contacting elements. The Poisson's ratio is $v$ and the modulus of elasticity of the two contacting materials is $E$. The equivalent radius of curvature in the plane of rotation is $R_{x}$.

The minimum film thickness can be obtained by the following formula [12]:

$$
h_{\text {min }}=3.63 \bar{U}_{r}^{0.68}\left(\alpha E_{e q}\right)^{0.49} \bar{W}^{-0.073}\left(1-e^{-0.68 k}\right) .
$$

The three capacitances can then be calculated from the following two equations derived from the parallel-plate capacitor model:

$$
\begin{gathered}
C_{H z, i}=\epsilon_{0} \epsilon_{f} \frac{\pi a b}{h_{c}} \\
C_{e n, i}+C_{e x, i}=2 \pi \epsilon_{0} \epsilon_{e} \int_{a}^{r} \frac{\frac{b}{a} x}{h_{c}+h(x)} d x, h(r)=100 h_{c},
\end{gathered}
$$

where $\epsilon_{0}$ is the vacuum dielectric constant, $\epsilon_{f}$ and $\epsilon_{e}$ the relative dielectric constant of lubricant film in Hertzian area and entrance/exit area, respectively. Radii of the ellipse are denoted by $a$ and $b$. The distance between the outer surface of the ball and the inner surface of the ring at $x$ is denoted by $h(x)$.

The resulting capacitance of the steel ball bearing can be written as:

$$
C_{b}=\sum_{n=1}^{N_{b}} C_{H z, i}+\left(C_{e n, i}+C_{e x, i}\right)+C_{o t h},
$$

where $C_{\text {oth }}$ accounts for the additional capacitances introduced by metal seals and/or ball retainer.

Equation (8) includes unknown parameters, such as $\epsilon_{f}, \epsilon_{e}$ and $C_{o t h}$, which are difficult to be accurately determined in practice, even when the operating temperature, bearing speed and load are given. Assuming $\epsilon_{f}=\epsilon_{e}=2.88$ and $C_{o t h}=0 \mathrm{pF}$, the calculated contact angle, film thicknesses and capacitances of a deep-groove steel ball bearing at 1,200r/min with three pure axial loads are tabulated in TABLE I.

To determine the unknown $\epsilon_{f}, \epsilon_{e}$ and $C_{o t h}$, at least 3 experimental measurements of the capacitance are required for a basic least squares regression analysis. More measurement

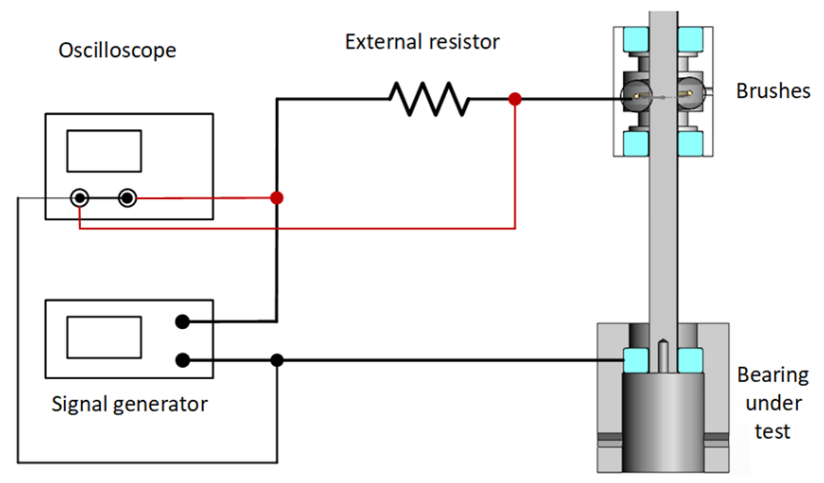

(a)

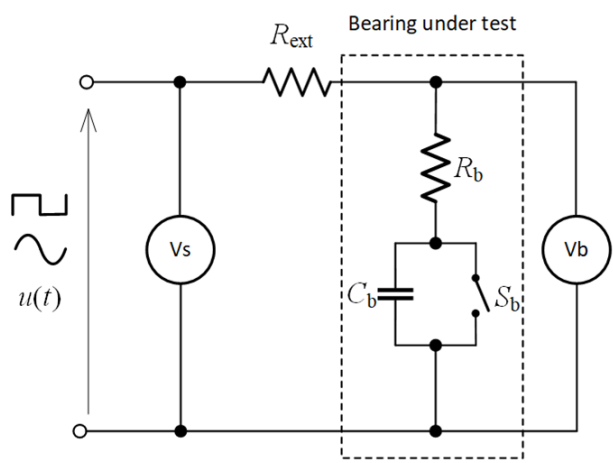

(b)

Fig. 4. Schematic diagram of the bearing capacitance measurement

data are likely to improve the accuracy and provide better predictions of bearing capacitance under various operating conditions.

\section{EXPERIMENTAl MEASUREMENTS FOR COEFFiCIENT DETERMINATION}

The schematic diagram of the bearing capacitance measurement and its equivalent circuit are shown in Fig. 4. The bearing test fixture is installed vertically so that pure axial load can be applied to the bearing under test.

The signal generator produces a step voltage signal or a pure sinusoidal voltage signal. An external high-precision resistor with a constant resistance is connected in series with the bearing under test through a mercury coupling, i.e., the brush in Fig. 4a. The amplitude of the applied voltage signal is set to a relatively low value to avoid the lubricant film breakdown. The time constant and the ratio between the bearing voltage and the step voltage input can be measured to calculate the bearing capacitance $C_{b}$ and resistance $R_{b}$, as demonstrated in [10]. Alternatively, the waveforms for the bearing voltage and the high-frequency sinusoidal voltage input can be recorded by a oscilloscope and used to calculate the bearing capacitance and resistance.

The measured voltages of a deep-groove steel ball bearing 6201 with two metal seals under $0 \mathrm{~N}, 49 \mathrm{~N}$ and $98 \mathrm{~N}$ additional axial loads are shown in Fig. 5. This type of bearing requires a load of at least $40 \mathrm{Nm}$ for operation. The sinusoidal voltage excitation is $10 \mathrm{MHz}$ and the bearing speed is $1,200 \mathrm{r} / \mathrm{min}$. 


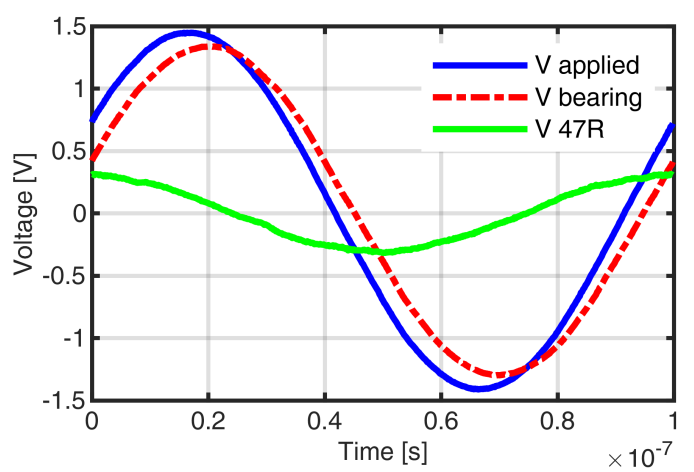

(a)

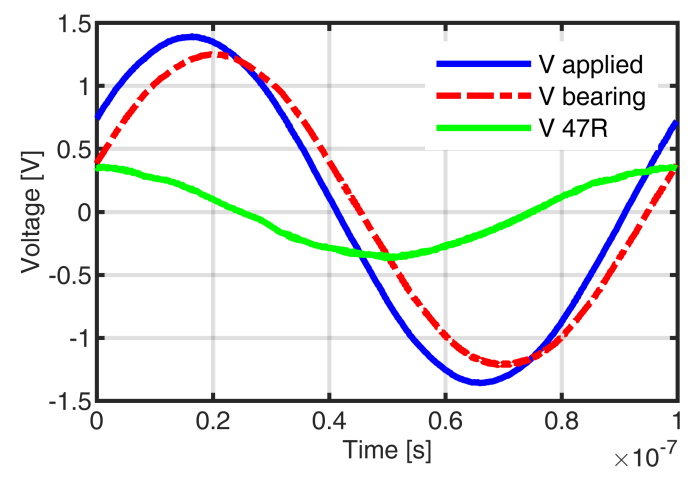

(b)

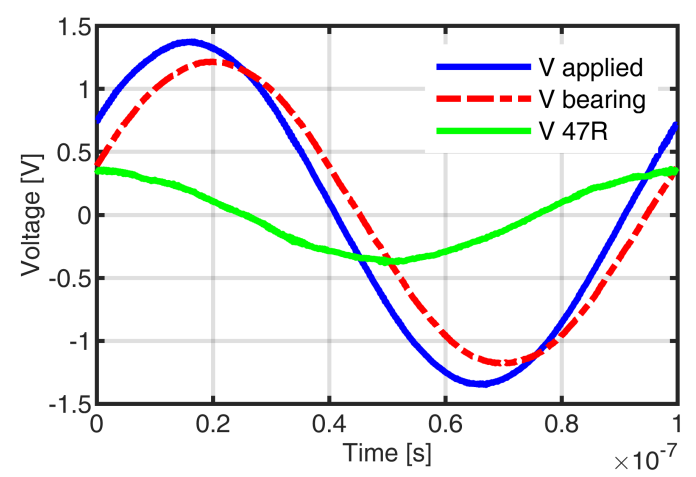

(c)

Fig. 5. Voltages with different axial loads: (a) no axial load $\left(C_{b}=78.2 \mathrm{pF}\right.$, $\left.R_{b}=5.4 \mu \Omega\right)$, (b) $49 \mathrm{~N}$ axial load $\left(C_{b}=95.7 \mathrm{pF}, R_{b}=4.7 \mu \Omega\right)$, (c) $98 \mathrm{~N}$ axial load $\left(C_{b}=99.2 \mathrm{pF}, R_{b}=5.3 \mu \Omega\right)$.

The calculated bearing capacitances and resistances are also provided. It can be seen that the resistance is nearly constant at approx. $5 \mu \Omega$ while the capacitance increases with the axial load.

Based on equation (8) and the measured results from Fig. 5, the optimal $\epsilon_{f}, \epsilon_{e}$ and $C_{o t h}$ can be determined by minimizing $\left(C_{b}^{\text {calc }}-C_{b}^{\text {meas }}\right)^{2}$ with three constraints: $1 \leq \epsilon_{f} \leq 5,1 \leq \epsilon_{e} \leq$ 5 , and $C_{\text {oth }} \geq 0$. With the optimized coefficients, the calculated bearing capacitance and its breakdown are tabulated in TABLE II.

The measured capacitance for the hybrid ceramic ball bearing 6201 with metal seals is $12.22 \mathrm{pF}$. The FE predicted values are $6.17 \mathrm{pF}$ and $12.75 \mathrm{pF}$, respectively, with and without metal seals, assuming the dielectric constant for the $S i_{3} N_{4}$ balls and
TABLE II

Contact ANgLe, Film THickNess and CAPaCitance BREAKdown at 1,200R/MIN WITH DIFFERENT AXIAL LOADS. REGRESSION ANALYSIS SHOWS THE OPTIMAL COEFFICIENTS ARE: $\epsilon_{f}=1.0, \epsilon_{e}=1.0 \mathrm{AND} C_{o t h}=$ $52.0 \mathrm{PF}$.

\begin{tabular}{cccccc}
\hline $\begin{array}{c}\text { Axial load } \\
{[\mathrm{N}]}\end{array}$ & $\begin{array}{c}C_{H z, i} \\
{[\mathrm{pF}]}\end{array}$ & $\begin{array}{c}C_{e n, i}+C_{e x, i} \\
{[\mathrm{pF}]}\end{array}$ & $\begin{array}{c}\text { Calc. } \\
{[\mathrm{pF}]}\end{array}$ & $\begin{array}{c}\text { Meas. } \\
{[\mathrm{pF}]}\end{array}$ & $\begin{array}{c}\text { Diff. } \\
{[\%]}\end{array}$ \\
\hline \multirow{2}{*}{0} & 0.45 & 4.65 & & & \\
\hline & 0.39 & 5.49 & 71.1 & 78.2 & -9.1 \\
\hline \multirow{2}{*}{49} & 8.28 & 4.66 & & & \\
& 6.31 & 5.49 & 95.2 & 95.7 & -0.5 \\
\hline & 12.08 & 4.66 & & & \\
98 & 9.22 & 5.49 & 106.8 & 99.2 & +7.7 \\
\hline
\end{tabular}

retainer is 10 . It is also found that the capacitance of ceramic ball bearings is insensitive to the dielectric constant of the ceramic material.

\section{Capacitance Prediction based on the Combined APPROACH}

With the proposed combined numerical and experimental approach, the capacitance breakdown in bearings and the influence of temperature, speed, and load can be studied. The impact of bearing speed on individual capacitances between balls and raceways illustrated in Fig. 6 shows that the capacitance for the entrance and exit region is nearly independent of the rotor speed. The capacitance for the Hertzian area, i.e., the lubricant film, decreases with the increase of bearing speed and keeps nearly constant in the speed range from $1,500 \mathrm{r} / \mathrm{min}$ to $2,000 \mathrm{r} / \mathrm{min}$. In addition, the capacitance between the ball and inner race is slightly larger than that between the ball and outer race due to the convex contact and thus smaller film thickness.

Both $\mu_{0}$ and $\alpha$ are temperature dependent. The impact of the temperature on the bearing capacitance is shown in Fig. 7. It can be seen that, for the specific bearing 6201 under test, the temperature variation has little impact on the bearing capacitance for light-load conditions. With more axial load, the capacitance increases slowly with the temperature rise.

\section{CONCLUSION}

This paper presents a new method to determine the capacitance of ball bearings based on combined numerical analysis and experimental measurements. The generalized equation for bearing capacitance calculation is developed from the physical construction of ball bearings. The unknown parameters, including the dielectric constant of the lubricant mixture, lubrication status, and additional capacitances, are determined experimentally. With the proposed approach, the capacitance breakdown in ball bearings and influences of temperature, speed and load are studied.

It is shown that the capacitance developed by the lubricant film varies significantly with the speed and load. Capacitances for entrance and exit regions, and the capacitance introduced by metal retainers and/or seals are nearly constant. The proposed method proves an effective tool to prediction bearing 


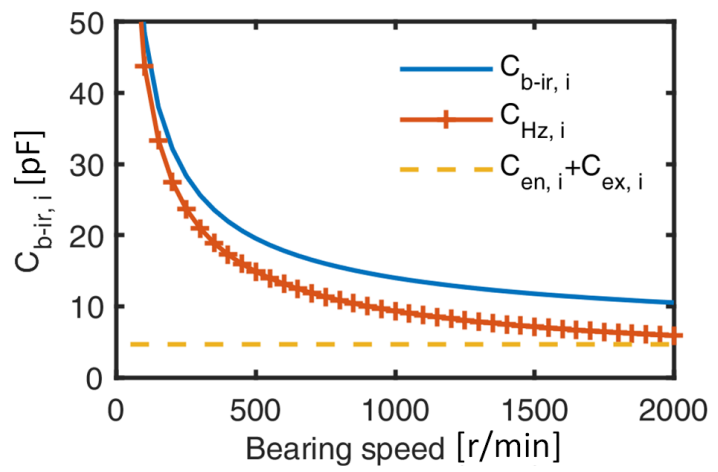

(a)

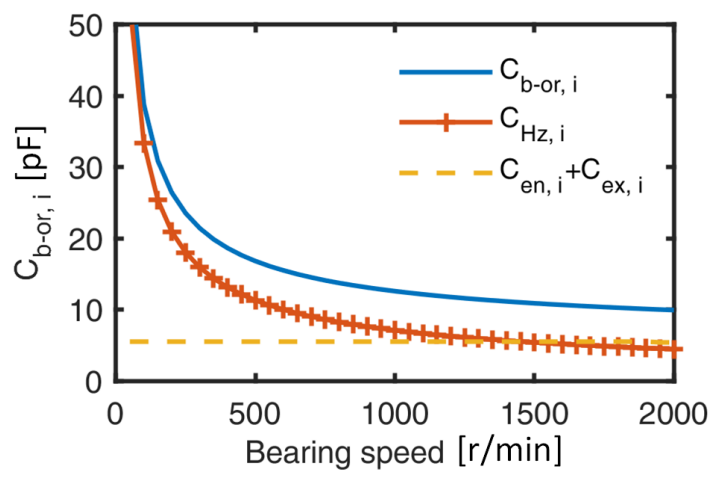

(b)

Fig. 6. Capacitances in bearing 6201 at different rotating speeds with an axial load of $49 \mathrm{~N}$, (a) capacitance between a single steel ball and the inner raceway, (b) capacitance between a single steel ball and the outer raceway.

capacitances under various operating conditions and will be used for bearing current prediction in wide speed and load ranges.

\section{ACKNOWLEDGMENT}

The support of Regal Beloit Corporation, University of Kentucky, the L. Stanley Pigman Endowment, and ANSYS Inc., is gratefully acknowledeged.

\section{REFERENCES}

[1] J. M. Erdman, R. J. Kerkman, D. W. Schlegel, and G. L. Skibinski, "Effect of PWM inverters on AC motor bearing currents and shaft voltages," IEEE Trans. Ind. Appl., vol. 32, no. 2, pp. 250-259, March 1996.

[2] A. Binder and A. Muetze, "Scaling effects of inverter-induced bearing currents in AC machines," IEEE Trans. Ind. Appl., vol. 44, no. 3, pp. 769-776, May 2008.

[3] J. Park, T. R. Wellawatta, S. Choi, and J. Hur, "Mitigation method of the shaft voltage according to parasitic capacitance of the PMSM," IEEE Trans. Ind. Appl., vol. 53, no. 5, pp. 4441-4449, Sep. 2017.

[4] T. Plazenet, T. Boileau, C. Caironi, and B. Nahid-Mobarakeh, "A comprehensive study on shaft voltages and bearing currents in rotating machines," IEEE Trans. Ind. Appl., vol. 54, no. 4, pp. 3749-3759, July 2018 .

[5] Shaotang Chen, T. A. Lipo, and D. W. Novotny, "Circulating type motor bearing current in inverter drives," in Rec. IEEE Ind. Appl. Soc. Annu. Meeting, vol. 1, Oct 1996, pp. 162-167 vol.1.

[6] J. Adabi, F. Zare, A. Ghosh, and R. D. Lorenz, "Calculations of capacitive couplings in induction generators to analyse shaft voltage," IET Power Electron., vol. 3, no. 3, pp. 379-390, May 2010.

[7] M. Schuster, D. Masendorf, and A. Binder, "Two PMSMs and the influence of their geometry on common-mode bearing currents," in Proc. Int. Conf. Electr. Mach. (ICEM), Sep. 2016, pp. 2126-2132.

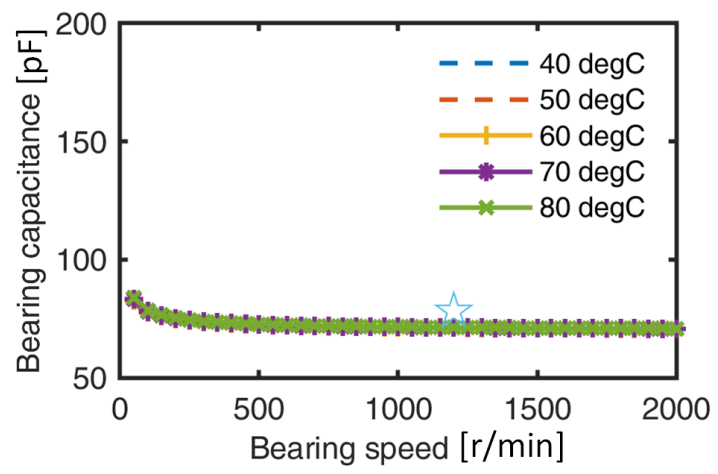

(a)

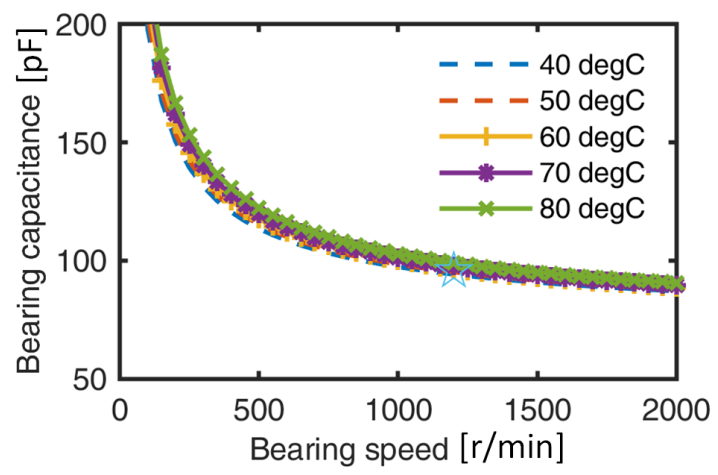

(b)

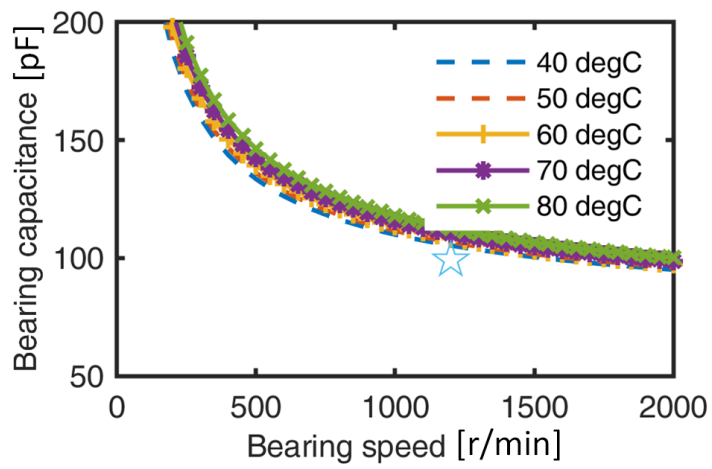

(c)

Fig. 7. Capacitances for bearing 6201 with different axial loads: (a) no axial load, (b) $49 \mathrm{~N}$ axial load, (c) $98 \mathrm{~N}$ axial load. The measured results are identified through markers.

[8] Y. Xie, J. Zhang, F. Leonardi, A. R. Munoz, M. W. Degner, and F. Liang, "Modeling and verification of electrical stress in inverter-driven electric machine windings," IEEE Trans. Ind. Appl., vol. 55, no. 6, pp. 58185829, 2019

[9] O. Magdun and A. Binder, "Calculation of roller and ball bearing capacitances and prediction of EDM currents," in Proc. IEEE Ind. Electron. Annu. Conf., Nov 2009, pp. 1051-1056.

[10] E. Wittek, M. Kriese, H. Tischmacher, S. Gattermann, B. Ponick, and G. Poll, "Capacitances and lubricant film thicknesses of motor bearings under different operating conditions," in Proc. Int. Conf. Electr. Mach., Sep. 2010, pp. 1-6.

[11] Y. Isomura, K. Yamamoto, S. Morimoto, T. Maetani, A. Watanabe, and K. Nakano, "Study of the further reduction of shaft voltage of brushless DC motor with insulated rotor driven by PWM inverter," IEEE Trans. Ind. Appl., vol. 50, no. 6, pp. 3738-3743, Nov 2014.

[12] A. Harnoy, Bearing Design in Machinery: Engineering Tribology and Lubrication. CRC Press, 2002. 